\title{
Multi-year Precipitable Water Vapor Observations in East Manila, Philippines using Radiosonde and Global Navigation Satellite System
}

\author{
Agana Louisse S. Domingo*, Ernest P. Macalalad \\ Department of Physics, Mapua University, Intramuros, Manila
}

\begin{abstract}
Precipitable water vapor (PWV) is a parameter that used to describe the water vapor content in the atmosphere has the potential to become a precipitation. Thus, it is important to measure PWV and investigate its trends and variability for potential forecasting precipitation. This study presents the

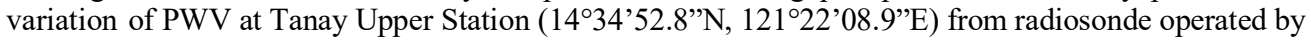
the Philippine Atmospheric, Geophysical and Astronomical Services Administration and at PIMO station (14³ '08.5'N, 12104'39.4'E) using Global Navigation Satellite System (GNSS) operated by NASAJet Propulsion Laboratory under the International GNSS Service (IGS) network from 2015-2017. Moreover, there is no significant difference ( $\mathrm{p}$-values $<0.05$ ) among PWV radiosonde, GNSS-PWV and rainfall as a function of year of observation. Monthly mean variation conforms to the Coronas climate classification, Climate Type I, in terms of the amount of precipitation. It is shown that PWV is high during wet months and least during dry months (November to April). Further, monthly mean variation is moderate correlated with surface temperature from radiosonde $(\mathrm{R}=+0.589)$. Evaporation rate depends on the surface temperature, which contributes in forming water vapor. The results showed that PWV from radiosonde gave reasonable values to be considered during wet and dry season as well as the seasonal variation of rainfall.
\end{abstract}

\section{Introduction}

Numerous scientific papers have studied the role of atmospheric water vapor content as a greenhouse gas [14]. As the source of precipitation, water vapor is transport is crucial part in atmospheric water cycle [5]. However, water vapor content makes up only $5 \%$ of the air is highly variable in its distribution; that is; it fluctuates seasonally and regionally [6]. Because of this, investigating water vapor to predict weather trends and climate changes becomes extremely difficult. Various instruments were developed to measure precipitable water vapor (PWV). It is defined as the height of liquid water result from condensing all the water vapor in a column from the surface to the top of the atmosphere [7]. One of the instruments used to measure PWV is the radiosonde.

Radiosondes are balloon-borne instruments that measure temperature, pressure and humidity through a profile of the earth's atmosphere up to a height of approximately $30 \mathrm{~km}$ and transmit the observed data to a ground station [8]. It ascends twice a day (0000 UT and 1200 UT) and its operation is expensive. Because of these restrictions, it provides a low temporal and spatial resolution [9]. There are eight radiosonde stations in the Philippines and one station is located in Tanay, Rizal. However, there are only limited scientific reports that studied the obtained data from the radiosonde measurement at Tanay station [10-11].

On the other hand, global navigation satellite system (GNSS), typically used for navigation purposes, can also be used by to estimate PWV by using the satellite signal delays from the influence of atmosphere. The estimated PWV from GNSS is proven to agree with the measured PWV from radiosonde [1213]. One of the International GNSS Service (IGS) stations in the country is in Quezon City (north-eastern part of Metro Manila). However, there are only a few scientific papers that studied the PWV estimates using this station [14-16].

This study aims to investigate the temporal trends of PWV derived from radiosonde and GNSS, and its relation to rainfall amount, surface temperature and relative humidity in this area from 2015 to 2017 . Its monthly means and the seasonal variation of rainfall will be presented as well.

\section{Methodology}

PWV data from 2015 to 2017 are derived from the radiosonde and GNSS. The period of observation is chosen based on the availability of the data. All radiosonde profiles in the Tanay Station (Station ID \#98433, location: $14.5797^{\circ} \mathrm{N}, \quad 121.3313^{\circ} \mathrm{E}$,

* Corresponding author: alscdomingo@gmail.com 
$\sim 600$ masl)

used in this study are from the archive of the University of Wyoming (Available at: http://weather.uwyo.edu). This station belongs to the climate type that hastropical monsoon as classified by Köppen and Geiger. It has tropical, short dry season. Surface temperature and relative humidity at the surface are also derived from the radiosonde profile.

On the other hand, PWV derived from GNSS used a station in Quezon City (Station ID: PIMO, location: $14.635719^{\circ} \mathrm{N}, 121.077731^{\circ} \mathrm{E}, \sim 100$ masl) are derived from SuomiNet. SuomiNet is a university-based network that provides PWV values from IGS GNSS receivers. They also provide a collocated measurement of surface temperature and relative humidity. [16] Lastly, the accumulated rainfall was the data gathered in Tanay, Rizal maintained by Philippine Atmospheric Geophysical and Astronomical Services Administration (PAGASA) through an automatic rain gauge (ARG).

In this study, the daily, monthly and inter-annual variability of the PWV, surface temperature, relative humidity, and rainfall is presented. PWV from the two methods are correlated to each other to assess their consistency, and to their corresponding collocated meteorological parameters.

\section{Results and Discussion}

Figure 1 shows the daily variation of PWV from radiosonde and GNSS, and rainfall from 2015 to 2017. The relationship between rainfall and PWV can be used to describe the seasonal variation. In figure 1, it shows that the daily data of PWV radiosonde corresponds to the daily data of GNSS-PWV and describes the direct relationship between the rainfall and PWV from the two instruments. GNSS-PWV values are generally higher than PWV radiosonde which may be due to their difference in heights. Nevertheless, both follow the same trend as the accumulated rainfall. That is, PWV and rainfall are low during dry season (November to
April) and high during wet season (May to October). While most of the significant rainfall occur when PWV is high, this does not imply the occurrence of rainfall. Notice that there are high values of PWV but there is less rainfall. It is also observed that there is a decrease in PWV after a significant rainfall. It can be verified that the precipitation later in the day caused by the said decrease in PWV value. [17] There are several studies that have reported decrease of PWV after a rainfall event. [18-19].

Table 1 shows the significant difference existing among PWV radiosonde, GNSS-PWV and rainfall using ANOVA. Since the p-values of each year are less than the level of significance 0.05 , this rejects the null hypothesis and tells that there is no significant difference. This indicates that the trend in these years is the same which agrees to the climate type of Tanay in terms of precipitation. In addition, the $\mathrm{F}$ values are more significant than F-critical values which statistically supports this claim. Each factor has high chance to depend on each other which proves that PWV can be utilized to forecast weather.

Table 1. The analysis of variations of PWV radiosonde, GNSS-PWV and rainfall.

\begin{tabular}{|c|c|c|c|}
\hline Year & F & F-critical & p-values \\
\hline 2015 & 51.09 & 3.28 & $7.86 \mathrm{E}-11$ \\
\hline 2016 & 80.71 & 3.28 & $1.96 \mathrm{E}-11$ \\
\hline 2017 & 175.83 & 3.28 & $2.52 \mathrm{E}-18$ \\
\hline
\end{tabular}

Figure 2 shows the correlation of monthly mean values of PWV radiosonde and GNSS-PWV to the monthly mean values of rainfall. It shows a moderate positive correlation between PWV radiosonde and rainfall $(\mathrm{R}=+0.631)$ and between GNSS-PWV and rainfall $(\mathrm{R}=+0.623)$ indicate that $\mathrm{PWV}$ can be used to relate with rainfall. Additionally, it has been known that the accuracy level of the PWV-derived from GPS signals is almost equal to that of radiometer or radiosonde [20].

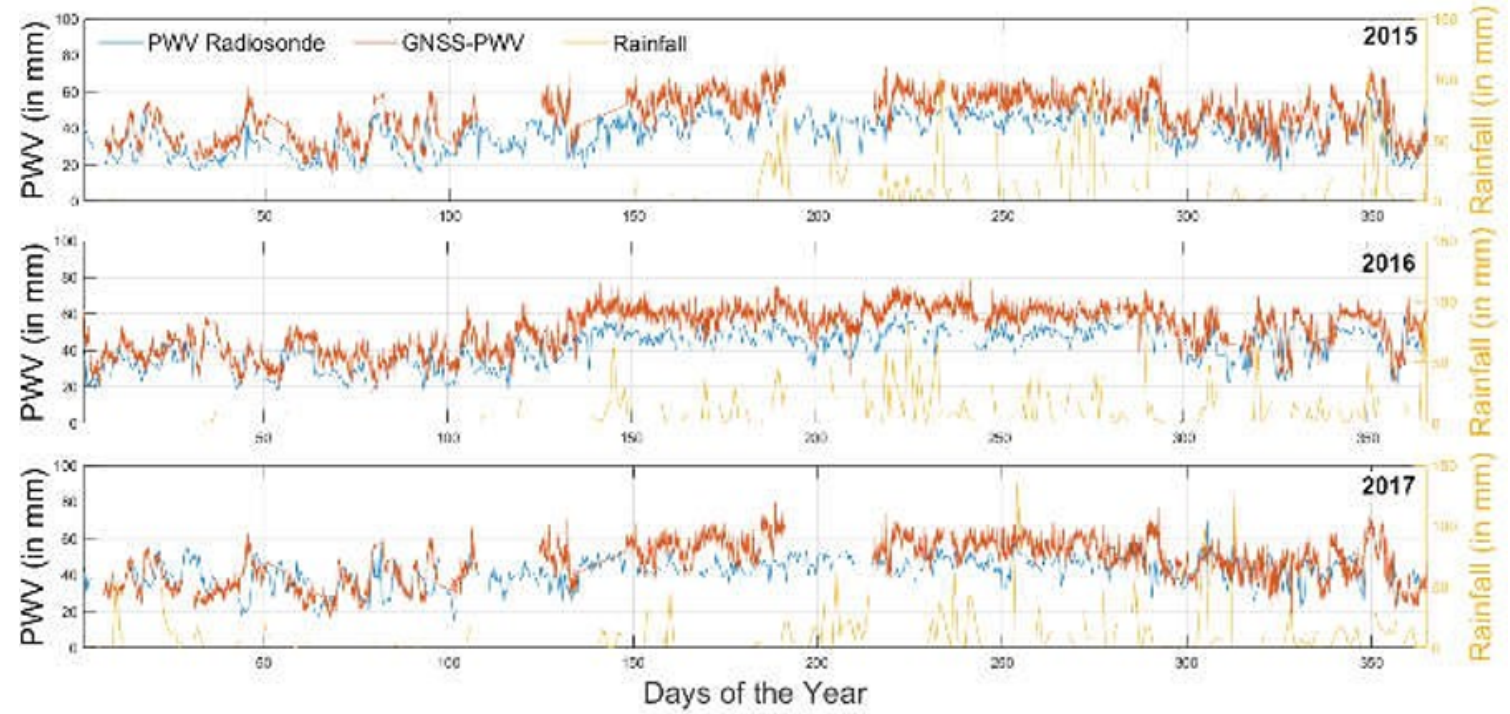

Figure 1. Daily data of the PWV radiosonde and GNSS-PWV (top) and daily data of rainfall (bottom). 


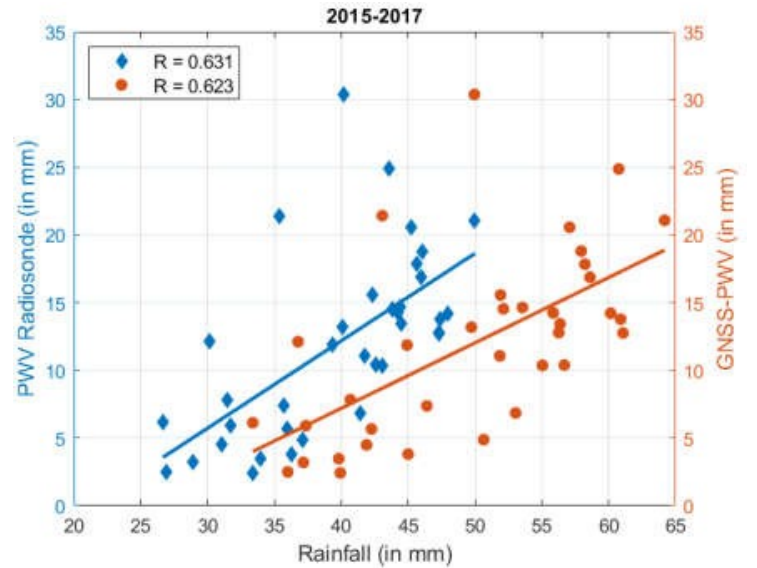

Figure 2. Correlation of monthly mean of PWV radiosonde (primary axis) and monthly mean of GNSS-PWV (secondary axis) to the monthly mean values of rainfall.

Monthly mean values of PWV radiosonde and GNSSPWV along with the collected rainfall from year 20132015 are shown in the figure 3. PWV radiosonde monthly mean values typically ranged from $25 \mathrm{~mm}$ to $50 \mathrm{~mm}$ while GNSS-PWV ranged from $10 \mathrm{~mm}$ to 60 $\mathrm{mm}$. The PWV is high from May to October and low for the rest of the months. These PWV values agree that the climate type of Tanay has two seasons: wet from midMay to October and dry for the rest of the months. The collected rainfall during wet season ranged from 300 to $600 \mathrm{~mm}$ while rainfall during dry season ranged from 2 to $400 \mathrm{~mm}$. This is primarily due to the two monsoons that cause a change in precipitation which are known as the southwest (SW) monsoon and from late May to September and the northeast (NE) monsoon from November to March. The western Philippines has a clear summer monsoonal rainfall regime with low rainfall from late November to April and peak rainfall from midJune to mid-September [21].

The variability during wet season ranged from $4 \mathrm{~mm}$ to $8 \mathrm{~mm}$ even so PWV is high while during wet season, although PWV is low, it has high variability that ranged from $6 \mathrm{~mm}$ to $12 \mathrm{~mm}$. This indicates that during wet season especially during peak of the SW monsoon and typhoon season in the area, whereas there is occasional increase in moisture due to sporadic weather events such as localized thunderstorms may have contributed to the high variability of PWV during dry season [2224].

Rainfall increased around May to June and decreased around October to November [25]. The rainfall in May gradually increases due to the SW monsoon that starts around this month with moist lowlevel westerly wind. The onset of SW monsoon is characterized by a sudden spurt of rainfall activity during wet months. Furthermore, October is the transition month from southwest to northeast monsoon season [26]. The decreased rainfall in November is likely because of this monsoon shift. Meanwhile, the increased rainfall in December and January determines the result of NE monsoon, competing with the SW monsoon in September and October. However, there is no distinct variation from the monthly rainfall from the dry months of December to April. Although PWV in these months have continual pattern, it does not have this kind of variation during monsoon months. Variation in PWV is only observed during premonsoon periods.

Figure 4 shows the correlation of monthly mean values of PWV radiosonde and GNSS-PWV to its monthly means of surface temperature and relative humidity. The surface temperature in the radiosonde $(\mathrm{R}$ $=+0.589)$ is moderately correlated to its PWV while in
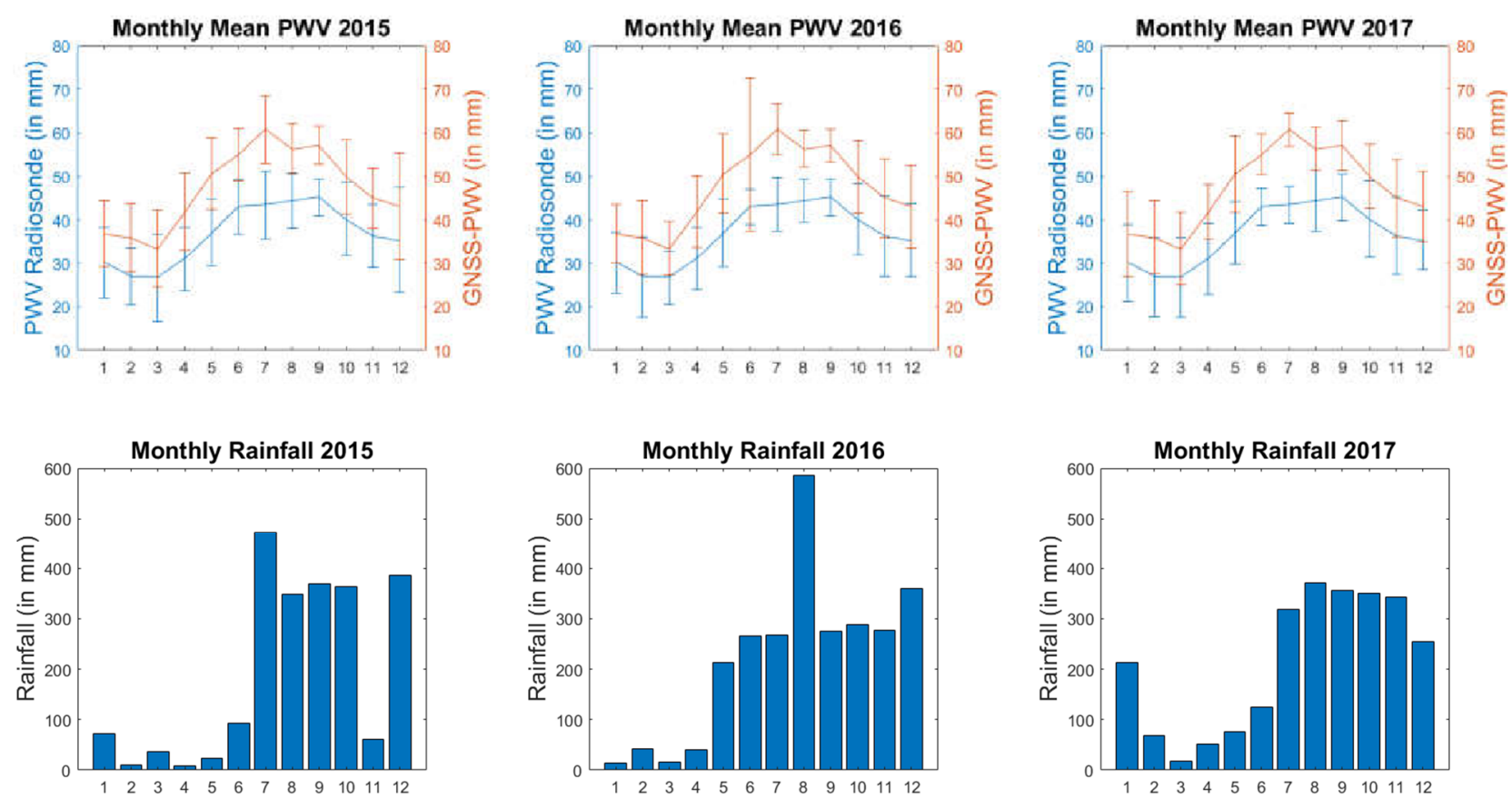

Figure 3. Monthly mean variations of PWV radiosonde and GNSS-PWV (top row) and monthly collected rainfall (bottom row) from 2015-2017. 

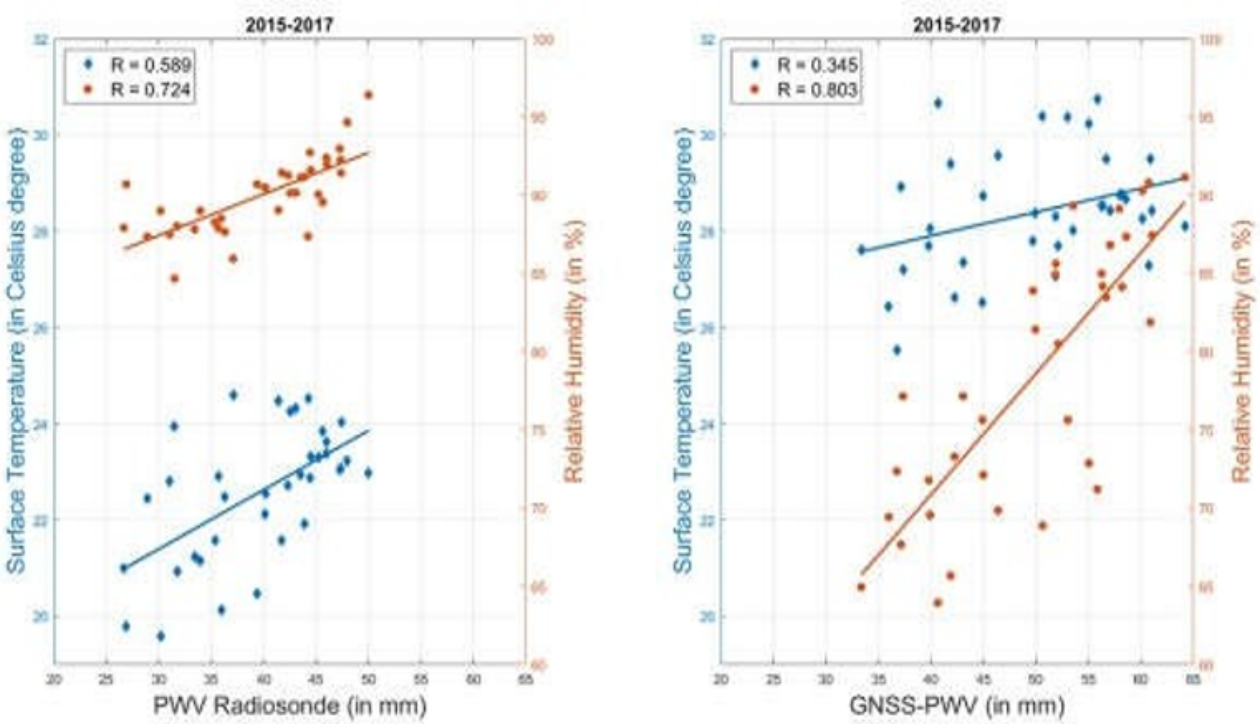

Figure 4. Correlation of monthly mean variation of PWV radiosonde (left) and GNSS- PWV (right) to its surface temperatures (primary axis) and relative humidity (secondary axis).

the GNSS $(\mathrm{R}=+0.345)$, it is weakly correlated. Notice that the surface temperature in the radiosonde is colder than the GNSS. The radiosonde is operated at the top of the mountain while the GNSS receiver takes place at the ground. These correlations show that water vapor is mainly related to surface temperature. With the increasing of water vapor, it results to higher moisture of air. Also, it is found that PWV radiosonde and relative humidity $(\mathrm{R}=+0.724)$ are moderately correlated but GNSS-PWV and relative humidity $(\mathrm{R}=+0.803)$ are strongly correlated. Lower temperatures in the summit region mean that equivalent changes in absolute vapor pressure have a larger effect on relative humidity. [26] This confirms that PWV is also a parameter in describing moisture content in the air.

\section{Summary}

Based on the analysis of the radiosonde profiles from 2015-2017 in Tanay station and the PWV estimated in GNSS in PIMO station, it evidently shows that the PWV conformed with the seasonal variation of rainfall data which agreed to the climatic classification of DOSTPAGASA in terms of precipitation. PWV gave acceptable values during dry and wet seasons. It is at peak from May to October and at bare minimum from November to April. On the other hand, wet season showed small variability while dry season were observed to have large variability.

As monsoons dominate the weather in each period, the amount of precipitation varies during and after the transition. Even so PWV has a recurring pattern, its behavior does not have distinct variation during the monsoon as the rainfall does. However, a variation in PWV occurred during pre-monsoon periods. Moreover, PWV and collected rainfall are statistically significant. Therefore, PWC influences on the collected rainfall. In this study, monthly mean variation of PWV in radiosonde exhibited a moderately correlation to relative humidity $(\mathrm{R}=+0.724)$ and surface temperature $(\mathrm{R}=$
+0.589 ). Meanwhile, the monthly mean variation of GNSS-PWV is strongly correlated to the relative humidity $(\mathrm{R}=+0.803)$ and low positively correlated to surface temperature $(\mathrm{R}=+0.345)$. This shows the dependence of evaporation rate to the surface temperature, which is accountable to the moisture content.

Since there is only a few scientific reports regarding with the radiosonde profiles in Tanay station, it is recommended to pursue the study by having additional data sets and analyzing the GNSS-PWV behavior in other near stations. Radiosondes must be operated continuously to avoid missing data because the meteorological parameters are needed to compute for PWV. The author may look into the data of other radiosonde and GNSS stations to make a more comprehensive study in the behavior of PWV.

\section{Acknowledgement}

The authors would like to acknowledge the Department of Atmospheric Science of University of Wyoming, UCAR and Suominet, and DOST-PAGASA for the data used in this study.

\section{References}

1. S. Phokate, IOP. Conf. Series. J. Phys. 901 (2017)

2. A. Dai, J. Wang, P. Thorne, D.E. Parker, L. Haimberger, X.L. Wang, J.Clim 24, 965-991 (2011) 3. S.W. Shivers, D.A. Roberts, J.P. McFadden, C. Tague, PloS ONE 14 (2019)

4. R.J. Ross, W.P. Eliot, J. Clim. 14, 1602-1613 (2001)

5. K. Trenberth, J. Clim. 12, 1368-1381 (1999)

6. S. Choy, C.S. Wang, T.K. Yeh, J. Dowson, M. Jia,

Y. Kuleshov, Adv. in Meteorol. 1-14 (2015)

7. A.J. Coster, A.E. Niell, F.S. Solheim, V.B. Mendes,

K.P. Buchmann, C.A. Upham, Presented at ION-GPS Kansas City, Kansas (2016) 
8. A.H. Dodson, W. Chen, N.T. Penna, H.C. Baker, J. Atmos. Sol-Terr. Phy. 63, 1331-1441 (2001)

9. M. Bevis, S. Businger, T.A. Herring, C. Rocken, R.A. Anthes, R.H. Ware, J. Geophys. Res. Atmos. D14 97, 15787-15801 (1992)

10. L. Dasallas, ISCEAS (2014)

11. W. Suparta, A. Iskandor, J. Asian Earth Sci. 5, 8895 (2012)

12. G. Gurbus, S. Jin, J. Clim. (2017)

13. H. Liang, Y. Cao, X. Wan, Z. Xu, H. Wang, H. Hui, Geod. Geodyn. 6, 2, 130-142 (2015)

14. F. Cruz, J. Villarin, Sci. Diliman 15, 84-87 (2003)

15. W. Suparta, A. Iskandar, M. Jit Singh, M.A. Mohd Ali, B. Yatim, Ann. Geophys. 56, 3 (2013)

16. E.P. Macalalad, R.V. Macalalad, $6^{\text {th }}$ IconSpace, 235-238 (2019)

17. R.H. Ware, D. Fulker, S.A. Stein, A.D. Anderson, S. Avery, R. Clark, K. Droegemeier, J.P. Kuettner, J.B. Minster, S. Sorooshian, Bull. Amer. Meteor. 81, 4, $677-$ 694 (2000)

18. K. Carnicer, E. Vallar, M.C. Galvez, Presented at the DLSU Research Congress (2016)

19. F. Cruz, J. Villarin, Sci. Diliman 15, 84-87 (2003)

20. R. Castilla, F. Plando, E. Vallar, M. Galvez, V. Morris, ACRS (2014)

21. C. Park, J. Baek, J. Cho. J. Astron. Space Sci. 27, 213-220 (2010)

22. V. Moron, A. Lucero, F. Hilario, B. Lyon, A. Robertson, D. DeWitt, Clim. Dyn. 33, 1159-1177 (2009)

23. V. Moron, A. Lucero, F. Hilario, B. Lyon, A. Robertson, D. DeWitt, Clim. Dyn. 33, 1159-1177 (2009)

24. R. Renju, C. Raju, N. Matthew, T. Anthony, K. Moorthy, J. Geophys. Res. Atmos. 4585-4599 (2015) 25. W. Jiang, P. Yuan, H. Chen, J. Cai, Z. Li, N. Chao, N. Sneeuw, Sci. Rep. 7, 1, 5874 (2017)

26. H. Kubota, R. Shiroka, E. Cayanan, F. Hilario, Progress in Earth and Planetary Sci. 427 (2017)

27. W. Duane, N. Pepin, M. Losleben, D. Hardy, Arct. Antarct. Alp. Res. 40, 2, 323-334 (2008) 